$\mathbb{T}$ periodica polytechnica

Transportation Engineering

41/2 (2013) $1 3 9 \longdiv { 1 4 2 }$

doi: $10.3311 /$ PPtr.7115

http://periodicapolytechnica.org/tr

Creative Commons Attribution (i)

RESEARCH ARTICLE

\section{Dynamic Analysis of Behavior of Three-axle Semi-trailer Road Tank Going on Special Waved Roadway}

\author{
Jan Peňáz / Ondřej Voltr
}

Received 2013-07-22

\begin{abstract}
This paper deals with the dynamic analysis of a truck with semi-trailer three-axle road tank for transport of loose materials like corn (barley, wheat, rye, oats, etc.). Firstly, the natural frequencies and mode shapes of truck-tank combination are calculated. Computer simulations of going on special waved road are performed for several speeds. Responses and maximum displacements are analyzed in vertical and lateral directions. These analyses represent a theoretical preparation of the experimental testing of the road tank. Obtained forces and reactions of these simulations may be used for the quasi-static analysis of deformation and stresses of the road tank. These results may also be used for extensive dynamic and fatigue analyses of the road tank and its behavior in real traffic conditions. Dynamic simulations of the simplified truck-tank model are carried out using software SIMULATION 2012 which is based on the finite element method (FEM).
\end{abstract}

\section{Keywords}

FEM $\cdot$ natural frequency $\cdot$ natural mode $\cdot$ road tank

\section{Acknowledgement}

The project presented in this article is supported by University of Pardubice, project number 51030/20/SG530001.

\section{Jan Peňáz}

Department of Mechanics, Materials and Machine Parts, Jan Perner Transport Faculty, University of Pardubice, Studentská 95, 53210 Pardubice 2, Czech Republic e-mail: jan.penaz@seznam.cz

\section{Ondřej Voltr}

Department of Mechanics, Materials and Machine Parts, Jan Perner Transport Faculty, University of Pardubice, Studentská 95, 53210 Pardubice 2, Czech Republic e-mail: ondrej.voltr@student.upce.cz

\section{Introduction}

Road transport is still the most popular and commonly used form of transportation of goods and materials. Therefore, it is necessary to produce road transport vehicles (trucks, semitrailers, etc.) of high quality. Excessive vibration of vehicles may affect road safety and lifetime of individual parts of the vehicles such as chassis, road tanks, etc. (Genta [3]; Vlk [6]). Vehicle behavior can be described in detail by computer simulations. In this way, it is possible to simulate extreme situations, for example sharp turning at high speed, driving on inclined plane, etc. The advantage of computer simulations is low price in comparison with the real tests of produced prototype vehicles. Comparison of computer simulations and real tests is crucial for the reliability of the results. The aim of this article can be summarized in a few points

- to create a computer dynamic model of the truck with semitrailer three-axle tank,

- to calculate the natural frequencies and modes,

- to perform the computer simulations of driving on special waved road for different speeds,

- to evaluate the response in maximum displacements in lateral and vertical directions.

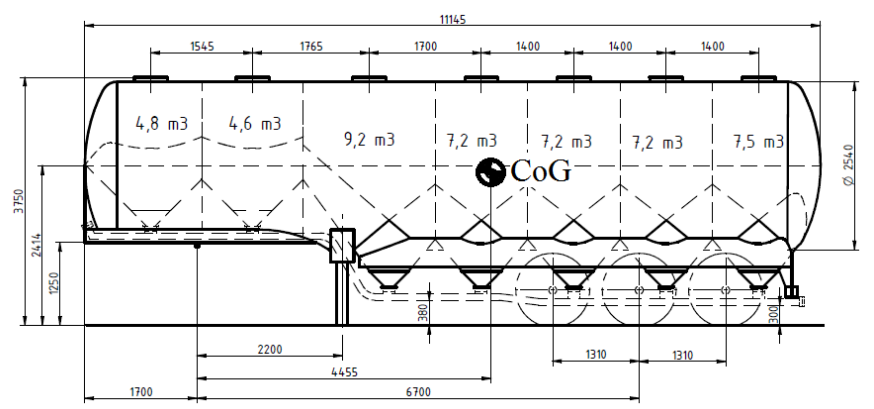

Fig. 1. Dimensions of NKA 46 road tank (with marked Centre of Gravity)

\section{Special waved roadway}

In this chapter, the special waved roadway is described. The waves on the roadway have triangular shape. Each wave is about 


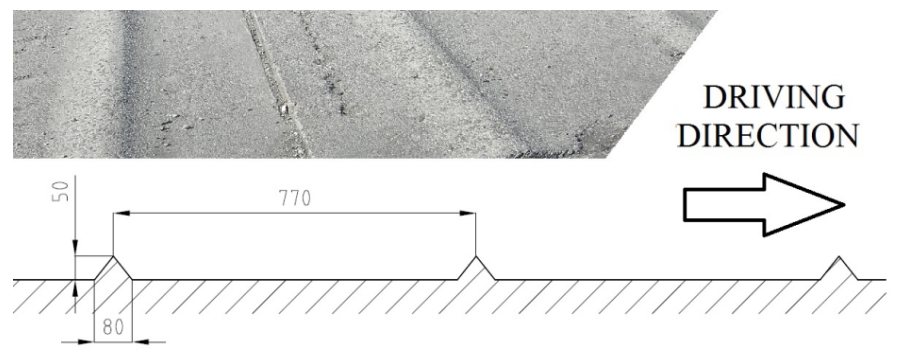

Fig. 2. Profile of roadway

$80 \mathrm{~mm}$ wide and $50 \mathrm{~mm}$ high. The distances between two waves are $770 \mathrm{~mm}$. The total number of waves is 26 in each computer simulation. Only right side of truck-tank assembly (right wheels) drives across these obstacles. Left side goes on smooth road all the time crossing the obstacles. This simulated roadway is similar to the special roadway at the test circuit in Kopřivnice (Czech Republic). This roadway is called "resonance roadway" inducing resonant vibration of the tested vehicles. During the computational analyses, the profile of roadway is simulated by means of a base excitation under each wheel. The shape of excitation impulse is given by the relationship of wheel position and time. Only kinematic excitation in the vertical direction is considered. All wheels are excited in a suitable phase shift which depends on the simulated speed.

\section{Dynamic truck-tank model}

This preliminary truck-tank model has to be simplified in comparison with the real truck-tank assembly. The model of the articulated vehicles (truck-tank) consists of several elementary 3-D objects (cylindrical shell and blocks). Main features of the model (mass, dimensions, centre of gravity position) are the same as the real tank (Paščenko, Stejskal [5]). The vehicle is modeled as a rigid body but the cylindrical shell has a real bending and torsion stiffness. The grain mass (loose material) is uniformly distributed along the whole tank. This material is considered a passive mass therefore it moves together with the tank. It also means that the tank is not dampened by movement of grain which is certainly conservative simplification. For the purposes of this study, the values of suspension stiffness and damping were adopted from literature. In a first approximation, these values are considered to be linear which simplification is again. A linear model of tires is used. One spring for each wheel represents the stiffness in the vertical, lateral and longitudinal directions. Their values are also used from literature. The modeled joint between the truck and tank should be similar to the real truck-tank joint (fifth wheel-king pin). The king pin allows relative rotation in all directions between the truck and semi-trailer. The mesh of model is quite coarse which is entirely sufficient for the study of dynamic behavior of the road tank.

The response of the tank is studied in three nodes. The first node (no. 1237, see Fig. 3) is near the truck-tank joint. The front part of the tank is strongly dependent on a movement of

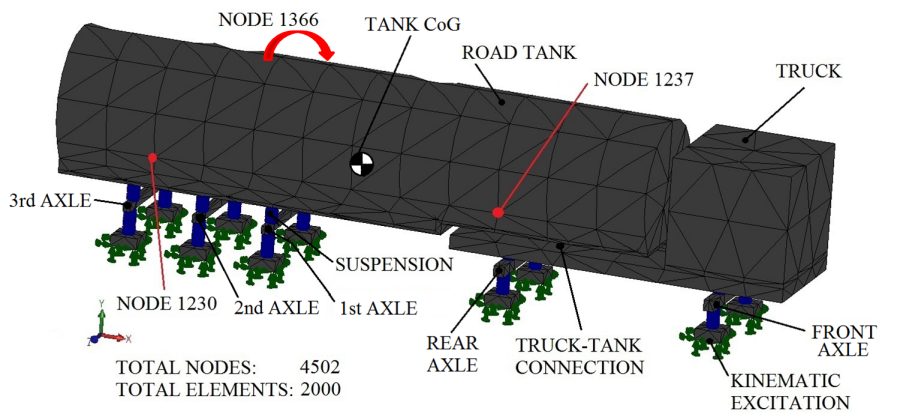

Fig. 3. Model and mesh

the truck. The second node (no. 1230) is placed at the rear part of the tank - near the second and the third tank axle. Both of these nodes are on the right side of the cylindrical shell. The rear part of the tank is not affected so much by the truck. The response of this part is dependent on damping and stiffness of the tank suspension. It is necessary to check also the left side to get better imagination about spatial 3-D behavior of the tank. The number of the third node is 1366 . It is placed on the cylindrical shell between the centre of gravity and the first tank axle. All nodes are in the same height (Paščenko, Stejskal [4]).

\section{Natural frequencies}

Firstly, it is necessary to find out natural frequencies and natural modes (Field, Hurtado, Carne, Dohrmann [1]; Field, Hurtado, Carne [2]). The frequency analysis is performed by means of the computational software SIMULATION. This analysis enables to calculate natural frequencies with corresponding natural modes and modal masses (Subspace Iteration Method). As the response to kinematic excitation of the model will be performed by Time Mode History Analysis (based on development of a dynamic response to the natural modes) the cumulative mass, which is a sum of modal masses of used natural modes, has to be at least $80 \%$ of the total mass for relevant results in each direction. Six natural frequencies and modes are considered. The cumulative mass of six considered natural frequencies in all three directions is about $97 \%$ (see Tab. 1).

Tab. 1. Natural frequencies and modal mass participation list

\begin{tabular}{|c|c|c|c|c|}
\hline Mode no. & Frequency $[\mathrm{Hz}]$ & X direction & Y direction & Z direction \\
\hline 1 & 0.665 & 0.000 & 0.000 & $\mathbf{0 . 6 6 5}$ \\
\hline 2 & 1.127 & $\mathbf{0 . 2 8 2}$ & 0.019 & 0.000 \\
\hline 3 & 1.281 & 0.001 & 0.000 & 0.004 \\
\hline 4 & 1.403 & 0.074 & $\mathbf{0 . 8 9 2}$ & 0.000 \\
\hline 5 & 2.188 & 0.002 & 0.000 & $\mathbf{0 . 3 0 6}$ \\
\hline 6 & 2.339 & $\mathbf{0 . 6 2 1}$ & 0.072 & 0.001 \\
\hline$\sum$ & & 0.980 & 0.983 & 0.976 \\
\hline
\end{tabular}

It is obvious that $1^{\text {st }}, 2^{\text {nd }}, 4^{\text {th }}, 5^{\text {th }}$ and $6^{\text {th }}$ frequencies and modes are significant. However, the modal mass of the third natural frequency is negligible. The resulting natural modes of the $1^{\text {st }}, 2^{\text {nd }}, 4^{\text {th }}, 5^{\text {th }}$ and $6^{\text {th }}$ natural frequencies are shown in Fig. 4 8. The difference between $1^{\text {st }}$ and $5^{\text {th }}$ mode lies in the fact that $1^{\text {st }}$ mode has the roll centre at the bottom (under axles) and $5^{\text {th }}$ mode has the roll centre at the top of the tank. 


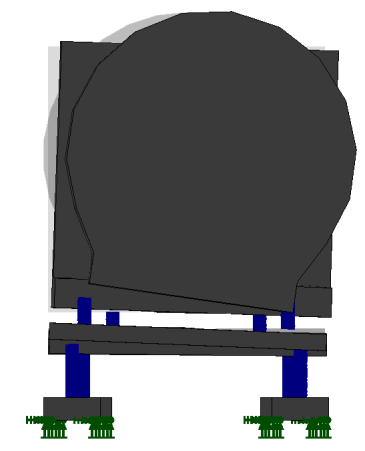

Fig. 4. $1^{\text {st }}$ mode - roll

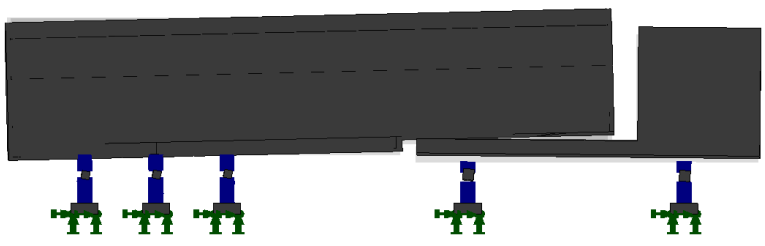

Fig. 5. $2^{\text {nd }}$ mode - pitch (tank) \& bounce (truck)

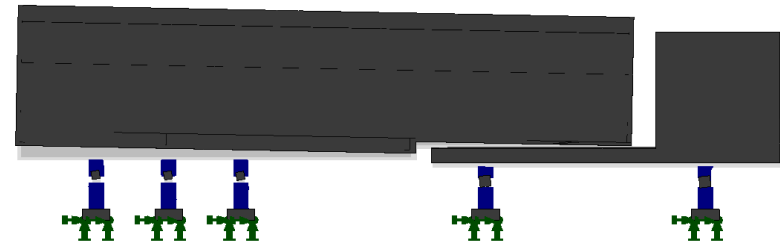

Fig. 6. $4^{\text {th }}$ mode - bounce (truck \& tank)

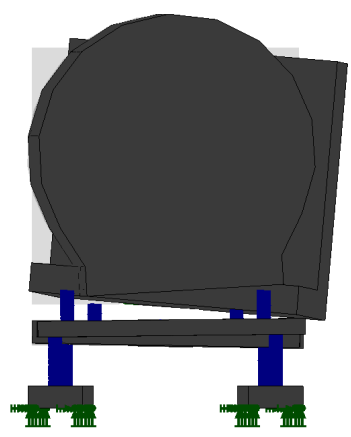

Fig. 7. $5^{\text {th }}$ mode - roll

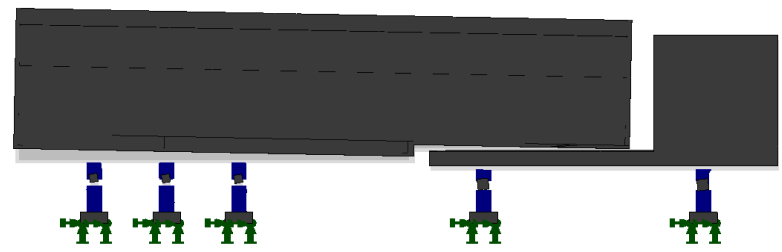

Fig. 8. $6^{\text {th }}$ mode - pitch (truck) \& bounce (tank)

\section{Computer simulations of going on special waved road}

Next, the resonant behavior is studied. It is necessary to calculate suitable speeds (right excitation frequencies) which correspond with significant natural frequencies. The resonance is achieved if the excitation frequency is in accord with the corresponding natural frequency. Then it is possible to simulate the most dangerous driving on the waved road. Next, other simulations are performed for speeds of $8,10,13,30 \mathrm{~km} / \mathrm{h}$ for better imagination about the tank behavior at higher speeds. The results are performed in Tab. 2 and Tab. 3

Tab. 2. Responses in maximum vertical displacements

\begin{tabular}{|c|c|c|c|c|c|}
\hline Mode & Frequency & Speed & $\begin{array}{c}\text { UY max } \\
(\mathbf{1 2 3 0})\end{array}$ & $\begin{array}{c}\text { UY max } \\
(\mathbf{1 2 3 7})\end{array}$ & $\begin{array}{c}\text { UY max } \\
(\mathbf{1 3 6 6})\end{array}$ \\
\hline & {$[\mathrm{Hz}]$} & {$[\mathrm{km} / \mathrm{h}]$} & {$[\mathrm{mm}]$} & {$[\mathrm{mm}]$} & {$[\mathrm{mm}]$} \\
\hline 1 & 0.665 & 1.8 & 10.529 & 11.814 & -7.680 \\
\hline 2 & 1.127 & 3.1 & 8.443 & 10.248 & -4.320 \\
\hline 4 & 1.403 & 4.0 & 6.286 & 6.026 & 3.776 \\
\hline 5 & 2.188 & 6.1 & 7.008 & 6.250 & 3.426 \\
\hline 6 & 2.339 & 6.5 & 5.936 & 5.822 & -2.073 \\
\hline & & & & & \\
\hline- & 2.857 & 8 & 5.342 & 5.321 & -1.912 \\
\hline- & 3.571 & 10 & 6.132 & 5.828 & 2.006 \\
\hline- & 4.762 & 13 & 7.621 & 7.057 & 2.239 \\
\hline- & 11.111 & 30 & 10.738 & 9.447 & -2.764 \\
\hline
\end{tabular}

Tab. 3. Responses in maximum lateral displacements

\begin{tabular}{|c|c|c|c|c|c|}
\hline Mode & Frequency & Speed & $\begin{array}{c}\text { UZ max } \\
(\mathbf{1 2 3 0})\end{array}$ & $\begin{array}{c}\text { UZ max } \\
(\mathbf{1 2 3 7})\end{array}$ & $\begin{array}{c}\text { UZ max } \\
(\mathbf{1 3 6 6})\end{array}$ \\
\hline & {$[\mathrm{Hz}]$} & {$[\mathrm{km} / \mathrm{h}]$} & {$[\mathrm{mm}]$} & {$[\mathrm{mm}]$} & {$[\mathrm{mm}]$} \\
\hline 1 & 0.665 & 1.8 & -9.506 & -9.085 & -7.253 \\
\hline 2 & 1.127 & 3.1 & -9.672 & -11.244 & -3.244 \\
\hline 4 & 1.403 & 4.0 & -2.708 & -2.293 & -2.036 \\
\hline 5 & 2.188 & 6.1 & -5.448 & -3.878 & -4.714 \\
\hline 6 & 2.339 & 6.5 & -2.610 & -2.411 & -2.463 \\
\hline & & & & & \\
\hline- & 2.857 & 8 & -2.013 & -2.139 & -1.983 \\
\hline- & 3.571 & 10 & -2.378 & -2.404 & -2.306 \\
\hline- & 4.762 & 13 & -2.952 & -3.371 & -2.764 \\
\hline- & 11.111 & 30 & -4.463 & -4.404 & -4.237 \\
\hline
\end{tabular}

In vertical direction, the amplitude ratio between displacements induced by obstacle excitation and tank response displacements is not higher than 0.24 . The maximum response is excited at speeds 1.6 and $3.1 \mathrm{~km} / \mathrm{h}$ due to resonance. Driving at these low speeds is not frequent. These speeds are achieved essentially only during starting and stopping vehicle. As the inertial forces are small, it is not so dangerous for the tank lifetime. Similar vertical displacements are also induced at higher speeds - for example $30 \mathrm{~km} / \mathrm{h}$ (see Tab.2 and Tab.3). However, in contrary to the previous case, the higher inertial forces can gradually damage truck or semi-trailer tank. 


\section{Conclusion}

The simplified FEM model is used for dynamic analyses of the behavior of semi-trailer road tank. The natural frequencies and modes of truck-tank assembly are investigated. The $1^{\text {st }}, 2^{\text {nd }}$, $4^{\text {th }}, 5^{\text {th }}$ and $6^{\text {th }}$ frequencies and modes are significant. Computer simulations of driving on special waved roadway are performed. Maximum displacement in $\mathrm{Y}$ and $\mathrm{Z}$ directions is found. The maximum response is excited at speeds 1.6 and $3.1 \mathrm{~km} / \mathrm{h}$ due to resonance. This study represents only the first stage of complex dynamic and fatigue analyses of the road tank and its behavior in real traffic conditions. The next stage of research will be devoted to a comparison of results in natural frequencies of the described computational model and the real road tank NKA 46 tested on a test polygon in Koprivnice (see Fig. 11. The strength and fatigue quasi-static analysis of the detailed computational model will then follow.

\section{References}

1 Field RV, Hurtado JE, Carne TG, Dohrmann CR, Structural dynamics Modeling and Testing of the Department of Energy Tractor/Trailer Combination, 15th International Modal Analysis Conference (IMAC), (Orlando, Florida, 1997), In: Proceedings of the 15th International Modal Analysis Conference (IMAC), 15th International Modal Analysis Conference (IMAC); Orlando, Florida, 1997, pp. 1994-2000.

2 Field RV, Hurtado JE, Carne TG, Analytical and Experimental Assessment of Heavy Truck Ride, 16th International Modal Analysis Conference (IMAC), (Santa Barbara, California, 1998), In: Proceedings of the 16th International Modal Analysis Conference (IMAC), 16th International Modal Analysis Conference (IMAC); Santa Barbara, California, 1997, pp. 965-972.

3 Genta G, Motor vehicle dynamics: modeling and simulation, Series on advances in mathematics for applied sciences: vol. 43, Vol. 43, World Scientific Publishing Co. Pte. Ltd., 1997, ISBN 13-978-981-02-2911-5.

4 Paščenko P, Stejskal P, Road tank NKA 46: Strength analysis - preparation of measurement in driving tests, Developmental report of $\mathrm{AK}$ Mechanika, AK- Mechanika; Pardubice, Czech Republic, 2008.

5 Paščenko P, Stejskal P, StudentCar: Dynamic and stress analysis, Partial research report - Ministry C6/2008/2b project. Support and personal development of talented students by building sports cars, University Pardubice, Jan Pernet Transport Faculty; Pardubice, Czech Republic, 2008.

6 VIk F, Dynamics of Moto Vehicles, Prof. Ing. František VIk D (ed.), Prof. Ing. František Vlk, DrSc.; Brno, 2005, ISBN 08-239-0024-2.

7 Dassault Systémes SolidWorks Corporation, SolidWorks SIMULATION 2012, 2012.

8 Parametric Technology Corporation, Mathcad, version 14. 